\title{
La política exterior de Estados Unidos en la campaña presidencial de Clinton y Trump. Los discursos sobre ISIS en la agenda mediática
}

\section{U.S. Foreign Policy in Clinton and Trump's presidential campaign. Discourses on ISIS in the media}

\author{
Isabel Rodríguez Toribio. Universidad Carlos III de Madrid (isartoribio@gmail.com) \\ Patricia González Aldea. Universidad Carlos III de Madrid (patricia.gonzalez.aldea@uc3m.es)
}

Resumen:

Durante la última campaña electoral en Estados Unidos el terrorismo del ISIS se ha convertido en la principal preocupación de la opinión pública (Gallup, 2015) y en el principal tema de política exterior de la campaña. El objetivo de este artículo es analizar los discursos sobre el ISIS de los candidatos Trump y Clinton publicados en los medios, así como investigar sobre la "construcción del otro", en este caso el ISIS, en dichos discursos. Como metodología se ha optado por un análisis cualitativo, basado en el análisis del discurso de noticias publicadas por medios digitales norteamericanos entre noviembre de 2015 y febrero de 2016. Entre los principales resultados destacan la estrategia provocativa, discriminatoria y populista de Trump, frente al tono apelativo y argumentativo de Clinton.

Palabras clave:

Política exterior; agenda mediática; campañas presidenciales; Estados Unidos; ISIS.

\section{Abstract:}

During the last Race for the White House in the United States of America, ISIS terrorism has become the main concern among public opinion (Gallup, 2015). This issue has also been the most significant topic addressed in the campaign speeches on foreign policy. This article analyses Trump and Clinton's discourses on ISIS within the media framework, as well as how this terrorist group and its acts are social constructed in the speeches. A qualitative methodology has been used. News published in the U.S. digital media, between November 2015 and February 2016, have been analysed through the critical discourse analysis theory. The main results of this research show how Trump has practiced a strategy based on provocation, discrimination and populism while Clinton has followed a much more argumentative and emotional path.

\section{Keywords:}

Foreign policy; media agenda; presidential campaign; United States; ISIS. 


\section{Introducción}

La carrera hacia la Casa Blanca en 2016, como toda campaña electoral, ha sido cubierta por los medios de comunicación ocupando gran parte de su programación. Pero los medios no han dedicado el mismo espacio y atención a todos los candidatos. Así, la cobertura mediática ha estado más centrada en el republicano Donald Trump que en cualquiera de los otros aspirantes a gobernar Estados Unidos, seguido por la demócrata Hillary Clinton. Según el analista Andrew Tyndal (2016), las cadenas $A B C, C B S$ y NBC desde que comenzó 2016 y hasta el 11 de marzo dedicaron 175 minutos para hablar de Trump, -teniendo en cuenta solo los días de semana- mientras que el resto de candidatos recibieron una atención mucho menor. A Hillary Clinton se le dedicaron en ese periodo un total de 60 minutos, seguida por Sanders con 44 minutos, y por último los republicanos Ted Cruz con 32 minutos y Marco Rubio con tan solo 14 minutos. Es decir, el tiempo que los medios de comunicación dedicaron a cuatro candidatos fue inferior al que acaparó Trump.

Según el sondeo de Gallup (Riffkin, 2015) del 14 de diciembre de 2015, el terrorismo era visto por los norteamericanos como el problema más importante de su país al que había que enfrentarse. Frente al 3\% que lo identificaba como tal en el mes de noviembre, en diciembre suponía ya el 16\% de las respuestas. Los ataques del 13 de noviembre de 2015 en París influyeron sin duda en esa percepción. Supuso el porcentaje más alto de preocupación dedicado al terrorismo en una década y se situó en plena campaña electoral como el tema que más preocupaba a los americanos por encima de otros como la economía, la forma de gobierno, o las armas. Además, se constataron diferencias entre seguidores de republicanos y de demócratas. El 24\% de los republicanos mencionó el terrorismo como el problema más importante a afrontar, frente a un $9 \%$ de los demócratas.

Es por esto que el terrorismo del ISIS ${ }^{1}$, -del inglés Islamic State of Iraq and Syria-, protagonizó numerosos enfrentamientos no solo entre los dos candidatos de los respectivos partidos a la Casa Blanca, sino entre sus propias filas. Hillary Clinton, a principios de este año, incrementó el uso de la política exterior y la seguridad nacional en sus discursos como estrategia electoral contra Sanders. La polémica campaña electoral de Trump centró también en el tema del ISIS algunas de sus declaraciones más criticadas, como la frase de Trump asegurando que "Obama y Clinton crearon el ISIS" (3 de enero 2016).

El 2 de marzo figuras importantes de la Administración de George Bush y de George W. Bush denunciaron en una carta abierta, firmada por numerosos miembros republicanos, que no compartían la visión y propuestas de Trump en política exterior. Los firmantes se mostraron disconformes con el punto de vista del candidato en cuanto a la inmigración, los musulmanes, la tortura o su admiración por el presidente de Rusia, Vladimir Putin.

1 Por razones metodológicas de los diferentes nombres con el que se conoce a este grupo terrorista se ha optado por ISIS. Los medios norteamericanos analizados emplean el término ISIS, frente a otros como DAESH o Islamic State. 
Por su parte el ISIS incrementó en los últimos meses su violencia y actos terroristas, ya no solo en zonas próximas a su territorio como Turquía, Yemen, Irak o Afganistán, sino también en Europa con matanzas como la de París o la de Bruselas, que conmocionaron al mundo occidental y consiguieron llamar la atención de los medios y la clase política internacional. En Estados Unidos el pasado 2 de diciembre, dos militantes del ISIS mataron a catorce personas en un ataque en San Bernardino, California. A esto, hay que sumarle la gran crisis de refugiados como consecuencia de todas las personas que huyen de la guerra de Siria y piden asilo en países del norte de Europa o Norteamérica, otro tema que también generó mucha controversia. Abu-Warda y Portaña (2011:131) afirman que "el modo en el que se conjuga el hecho noticioso y la intencionalidad política establecerá los paralelismos y las divergencias entre las estrategias de comunicación de los republicanos y demócratas".

La interacción entre las agendas políticas y mediáticas es mayor si cabe en campañas electorales. Los mensajes de los discursos electorales no llegan a la mayoría de los ciudadanos tal y como fueron elaborados en un principio, ya que se someten al filtro e interpretación de los medios. Weaver (1981) decía que la imagen inicial que dan los medios de los candidatos determinará las informaciones que se den a posteriori sobre ellos, algo de especial relevancia en el caso de nuevos candidatos, como ha sido Trump. The New York Times publicó el 15 de marzo de 2016 el artículo "\$2 Billion Worth of Free Media for Donald Trump" donde hablaba sobre la abismal diferencia de cobertura en los medios de comunicación a los candidatos a la presidencia durante esta campaña cuantificando lo que ha ganado Trump a cuenta de la publicidad gratuita que le hicieron los medios.

Son muchos los factores que determinan la estructura de la agenda política o institucional, destacando la acción del gobierno, el debate político o la ciudadanía. Kingdon (1984) señala que acontecimientos de primera magnitud como las guerras o unas olimpiadas son acciones que llenarían todas las agendas durante un tiempo. Por lo tanto "la guerra contra el terrorismo", -término que recuerda al de "guerra contra el terror" que es ya parte de la historia de la política exterior norteamericana-, como denominaron los propios candidatos a la cuestión del ISIS, era un tema susceptible de convertirse en parte del discurso político y estar en la agenda mediática. Y así ha sido.

El objetivo de este artículo es analizar los discursos en materia de política exterior, centrada en el ISIS, que los candidatos Trump y Clinton han pronunciado y la cobertura y enfoque que los medios de comunicación han hecho de ellos. Además teniendo en cuenta que la realidad se construye a través del lenguaje y la actividad discursiva, se trata de investigar acerca de la "construcción del otro", en este caso el ISIS, por parte de los candidatos.

Teniendo esto en cuenta, las dos hipótesis de partida son las siguientes:

- Republicanos y demócratas han construido en sus discursos la figura del "otro", la amenaza de ISIS y cómo combatirla de manera diferente, y los medios por su parte han trasladado a su agenda esa confrontación en los discursos. 
- El tono negativo y discriminatorio hacia toda la comunidad musulmana de los discursos republicanos de Trump contrasta frente al tono más neutro y argumentativo de los discursos demócratas de Clinton.

\section{Comunicación política y campañas electorales}

La política, el derecho o la educación, son algunas de las dimensiones sociales que, según el lingüista Van Dijk (2002), se construyen parcialmente con el discurso, a través del cual se transmiten ideologías, conocimientos o valores y se controlan actos e interacciones.

Siguiendo a Fairclough y Wodak (1997: 273) que consideran que "cualquier caso de uso lingüístico realiza una pequeña contribución a la reproducción o transformación de la sociedad y la cultura, incluyendo los mecanismos de poder", se puede hablar de que los discursos reproducen y transforman la realidad cuando se definen o califican las relaciones de rol interpersonales, se presentan identidades de individuos o se elaboran representaciones del mundo. Laborda (2012) añade que el discurso, tanto de carácter periodístico como institucional, puede construir determinadas banderas ideológicas que pueden acarrear consecuencias tales como la discriminación de ciertos grupos de ciudadanos.

"La comunicación es sin duda una pieza clave para conseguir un triunfo electoral, sustentar un liderazgo eficaz" (Mazzoleni y Winfried, 1999) y "no hay política sin comunicación” (Canel, 2006:17). En este sentido el discurso político, según García Beaudoux, D’Adamo y Slavinsky (2005:32), es “una construcción de carácter persuasivo que permite comunicar ideas y propuestas, referidas a objetos y/o públicos, tanto a través de palabras como imágenes, por lo que se dice explícitamente pero también por lo que se sugiere".

Fontencilla (1989) explica que el discurso político, además de estar sometido a la ideología de quien lo enuncia, suele caracterizarse por ser persuasivo con el público indeciso susceptible de sumarse a su causa, tener una parte dedicada al "nosotros" para reforzar el apoyo de sus seguidores, y hacer referencias a un "contradestinatario" de manera simultánea.

A la hora de elaborar un mensaje electoral hay que tener en cuenta la premisa "Es solo mi partido el que te puede ofrecer lo que necesitas" (Canel, 2006: 45), algo que lleva implícito el carácter de contienda y el enfrentamiento con todos los que no pertenezcan a la oferta electoral del candidato. Por lo tanto, parece que la oratoria política está estrechamente ligada con la polémica y esto hace necesario la construcción de un adversario. Los candidatos atacarán la posición de su contrincante respecto a ciertos temas para reafirmar sus políticas y propuestas.

La elección de las palabras que se utilizan a la hora de confeccionar estos mensajes es importante, ya que a través del lenguaje de los discursos se puede "argumentar y persuadir, establecer mecanismos de identificación y refuerzo, dotar de dramatización el discurso o crear etiquetas" (Denton y Woodward, 1998:51-53). Siguiendo con la importancia del lenguaje Pérez Herrero (2014: 249) afirma que son las palabras las que enmarcan el discurso porque "condicionan el contexto en 
el que se desarrolla la campaña. En el acierto de su elección radica en muchos casos que la agenda del candidato se imponga a la de los medios". Esto se debe a que hay palabras que causan rechazo, mientras que otras son capaces de generar simpatía tanto en los seguidores de la misma tendencia política como en los de la opuesta.

En cuanto al acierto a la hora de escoger el lenguaje y el conocer los marcos referenciales a los que evoca cada término, Chomsky (2003) cree que todo conocimiento producido se transmite a través de filtros políticos y culturales que representan unos intereses determinados y miedos colectivos. Como apunta Holloway (2002), la aceptación o el rechazo del mensaje estará condicionado por vivencias personales previas de la ciudadanía, por lo que conocer la historia de la audiencia a la que el candidato se dirige puede resultar de gran ayuda.

Los discursos de los candidatos en campaña electoral están sujetos a una estrategia que puede recurrir desde a la provocación del receptor, a su intimidación, a la apelación, o al empleo de la retórica del miedo. El miedo se utiliza en ocasiones para "destacar que, por su magnitud, el adversario constituye un verdadero peligro o amenaza" (García Beaudoux, D’Adamo y Slavinsky, 2005:186).

En esta línea, hay que tener en cuenta que las campañas sirven para movilizar el electorado, ganarse la confianza de votantes potenciales, reforzar lealtades, convertir a los electores que están más lejanos a nuestros ideales y neutralizar a los más adversos (Herrero y Requeijo, 2014), algo que puede propiciar la aparición de mensajes y discursos en clave populista. Siguiendo a Laclau (1977), un discurso populista es un discurso político pensado para movilizar a los ciudadanos en contra de un enemigo determinado y que sirve al candidato para postularse como líder en esta hazaña. Laclau (1977) advertía que los discursos políticos de corte populista convierten a quienes los escuchan en compatriotas, compañeros, o "nosotros". Patriau (2012) habla de que en muchos casos este "nosotros" se manifiesta a través del vocablo pueblo o nación, y se muestra como culpable a aquel que está fuera del grupo.

"Lo que diferencia a un discurso populista de cualquier otro y se vuelve clave a la hora del análisis de los discursos es interceptar la división social entre un nosotros enfrentado a un ellos. De un lado el pueblo y su voluntad y de otro los grupos comparativos que atentan contra ese pueblo" explica Hawkins (2010: 50). Siguiendo esto y a Patriau (2012), podrá ser considerado como discurso populista aquel que identifique a un enemigo, apele a un pueblo opuesto a ese enemigo y construya un líder desde abajo y poseedor de grandes cualidades que lo legitiman como salvador del pueblo.

Canel (2006) advierte, no obstante, de que los mensajes electorales, por lo general, no llegan a la población tal y como fueron elaborados por los partidos, sino que se distribuyen por la población a través de los filtros de los medios de comunicación, algo que hace que los políticos desarrollen técnicas informativas, con el fin de que sus mensajes parezcan noticia y sean retransmitidos por los medios. 


\section{Campañas electorales y medios de comunicación}

En toda campaña electoral están los ciudadanos, los candidatos y los medios de comunicación. En los últimos años los medios han ido ganando protagonismo e importancia en los procesos electorales, ya que se han convertido en el escenario principal en el que se enfrentan los políticos. Además, García Beaudoux, D’Adamo y Slavinsky (2005) explican que los periodistas pueden influir en la opinión pública y causar cambios en la agenda inicial de los candidatos.

Esta capacidad para interferir en la opinión pública fue denominada en 1972 por McCombs y Shaw como Agenda Setting, un término que hace referencia a la influencia que tienen los medios de comunicación, ya que los temas que ellos escogen como más importantes tienden a ser percibidos por la sociedad también como los asuntos que mayor interés tienen, algo que hará que los políticos sigan muy de cerca la agenda mediática a la hora de construir sus discursos. El nombre metafórico de Agenda Setting "proviene de la noción de que los mass media son capaces de transferir la relevancia de una noticia en su agenda a la de la sociedad" (McCombs y Bell, 1996:17). Seymour-Ure (1974) añadió al respecto que la prensa tiende a subrayar la polémica y a enfrentar a los candidatos.

Para elegir los "temas de campaña" la clave reside en "crear los mensajes de campaña a raíz de ciertos temas que se presume inclinarán a la ciudadanía a favor, dadas las predisposiciones y actitudes existentes en sondeos o encuestas” (García Beaudoux, D’Adamo y Slavinsky, 2005:77). Además de convertir estas cuestiones en "temas de campaña”, harán que los mensajes transmitidos sean más eficaces.

En campañas electorales funciona lo que apuntan Dearing y Rogers (1996:72), "la agenda política representa la llave maestra de todas las demás ya que genera nuevos temas que influenciarán tanto en la agenda de los medios como la pública". Así, los discursos e intervenciones políticas de los candidatos, son susceptibles de comunicarse en noticia y llegar, a través de los medios, a un gran número de personas.

En un primer nivel de la agenda se tenía en cuenta el contenido que destacaban los medios, pero hay un segundo nivel que engloba el estudio de los elementos más subjetivos o calificativos. Es decir, como explica McCombs y Bell (1996), este segundo nivel tiene en cuenta el encuadre o framing, que incluye también las respuestas emocionales. El framing hace especial hincapié en los enfoques que los periodistas hacen sobre una noticia, el punto de vista y la interpretación con la que se presentan los hechos. Según Etman (1993:52) "enfocar es seleccionar algunos aspectos de una realidad percibida y hacerlos sobresalir, de tal manera que se promueve una determinada definición del problema, una interpretación de la causa, una evaluación moral y la recomendación de una solución".

Los periodistas transmiten las noticias con un punto de vista determinado, seleccionan algunos aspectos de la realidad y los hacen sobresalir sobre el resto. Uno de los frames más estudiado ha sido el de la "Guerra contra el Terror" que fue promovido por la Casa Blanca. Como explican Reese y Lewis (2009) al principio consiguió un consenso entre los estadounidenses, los 
medios de comunicación y los líderes políticos. Aceptar este marco o premisa facilitó considerablemente el apoyo de la opinión pública a la agresiva política exterior de Bush en Irak y Afganistán, según explican Reese y Lewis (2009).

En 1987 Iyengar y Kinder hablan además sobre el efecto priming o de preparación del público con relación a ciertos asuntos de interés y exclusión de otros. Es decir, la prensa, TV y radio tienen la capacidad de preparar a los ciudadanos para responder de una determinada manera a un discurso político en concreto. Cuando un ciudadano tiene que ejercer un juicio de valor sobre un candidato o político, echará mano de todo lo que sabe de él, lo que guarda en su memoria o tiene más a mano, que según estos investigadores, será lo que han recibido a través de los media. El segmento de la población en el que el efecto priming se percibe con mayor incidencia, es el compuesto por ciudadanos de menor nivel de estudios. También consideraron que los votantes que se enfrentan a las informaciones que distribuyen los medios con una postura propia y firme son menos vulnerables a dicho efecto.

En la carrera hacia la Casa Blanca irrumpió de lleno el ISIS, y los candidatos se vieron forzados a incluirlo como parte esencial de la campaña y a redactar discursos y propuestas sobre ello.

\section{Política exterior y terrorismo: ISIS}

George W. Bush mantuvo una estrategia planificada y marcada, la que se conoció como "Guerra contra el terror", un concepto que sirvió para justificar la invasión de Irak en 2003, propició que se aceptasen versiones rígidas o autoritarias y se alimentasen prejuicios e intolerancia hacia los musulmanes (Lifton, 2003).

Además, en situaciones de conflicto, como fue la de Irak o es la actual con Oriente Medio, tienden a darse discursos en algunos políticos que incitan al odio o la discriminación y que al reproducirse por los medios pueden acarrear consecuencias. Que estos textos sean aceptados, permitidos y reproducidos hay que entenderlo dentro de lo que Alcácer (2015:48) considera el "Modelo americano" que "sostenido en la tradición cultural y política del liberalismo, opta por la tolerancia hacia el intolerante. Asumiendo como esencial para su democracia la neutralidad del Estado respecto a diferentes opiniones”.

Welch denunció en 2006 la campaña del gobierno estadounidense y los medios de comunicación que estaban difamando al islam y trataban con recelo a todos los musulmanes. Lo trágicos efectos de esa forma de etiquetamiento se estaban expandiendo y reforzando. En los últimos cien años ha habido, según el académico Tovar (2014), dos paradigmas que han marcado la esencia de la Administración Americana en cuanto a política exterior: el idealismo liberal Wilsoniano y el Realismo político. No obstante, la política exterior de Estados Unidos ha cambiado en los últimos quince años a consecuencia de los atentados del 11 de septiembre de 2011. La Administración Bush (enero 2001- enero 2009) cambió el discurso norteamericano en cuanto a política exterior. Cuando llegó a la presidencia lo hizo acompañado por la segunda generación de neoconservadores y con el discurso de que la mejor manera de conservar la supremacía de Estados Unidos a nivel global era a través de la fuerza. Para Busso (2002), tras el 11S se terminó con una Administración que en un principio esta- 
ba centrada en la política interna. La Estrategia de Seguridad Nacional de 2002 estadounidense expuso los puntos claves en los que se fundamentaría la política exterior del país, escrito al que se denominó “Doctrina Bush”. Estas decisiones en política exterior, sobre todo las relativas a Afganistán e Irak, son parte de las razones que condujeron a los Estados Unidos, como explican Valdés-Ugalde y Duarte (2013), a un caos económico y político que heredó Obama.

"He venido aquí para buscar una nueva relación entre Estados Unidos y los musulmanes del mundo". Con esta frase el 4 de junio de 2009 en la Universidad de El Cairo, Obama anunció un nuevo cambio en la política exterior estadounidense. Por su parte, la entonces Secretaria de Estado y actual candidata a la Casa Blanca, Hillary Clinton, defendió en 2009 el ejercicio de un "poder inteligente" que significaba utilizar de manera prudente los medios del país, tanto económicos como militares, su aptitud innovadora y las capacidades de credibilidad de Obama y su equipo.

Durante su segundo mandato, Obama ha tenido que hacer frente a sucesos de índole internacional como la aparición del autodenominado Estado Islámico, el conflicto con Irán, la crisis en Ucrania o la del Ébola en África que han generado incertidumbre a nivel global poniendo a prueba la figura de liderazgo de los Estados Unidos. En el último año y ya con la campaña electoral para unas nuevas elecciones, el principal problema con el que está teniendo que lidiar la Administración de Obama es con la creciente presencia del autodenominado Estado Islámico, sus ataques terroristas y las posibles consecuencias tanto en suelo americano como internacional. Algo que tendrá que afrontar también el nuevo presidente del gobierno estadounidense.

El resurgir de fundamentalistas del islam, con un gran protagonismo en el panorama internacional desde la última década del siglo XX, según Kepel (2000) ha determinado la conformación de un contexto geopolítico internacional nuevo. A este grupo pertenecería el grupo armado de terroristas que defiende la expansión a nivel global del que denominan ISIS.

Cronin avisaba en marzo de 2015 en el artículo "Por qué el contraterrorismo no va a acabar con la última amenaza terrorista”, publicado por Foreign Affairs, que el "ISIS no es Al Qaeda, no es una parte del movimiento. ISIS es su sucesor y representa la amenaza yihadista post Al Qaeda (que sigue teniendo peligro en el norte de África y en Yemen)". También criticaba que Washington ha sido muy lento al adaptar sus políticas en Irak y Siria y detectar la verdadera amenaza del ISIS, porque la estrategia del ataque terrorista que ha llevado Estados Unidos en estos países se centró en Al Qaeda y sus aliados, dándole ventaja al ISIS.

El 21 de diciembre de 2015 el New York Post publicaba una entrevista que había realizado a Obama, en la que culpaba a los medios de comunicación de publicitar al ISIS y del miedo que se había instaurado en la ciudadanía después de los ataques terroristas de París y San Bernardino. "Si habéis estado viendo la televisión en el último mes, todos habréis escuchado hablar de esos chicos con máscara y bandera negra que potencialmente vienen a por nosotros" dijo el presidente, a lo que añadió: "Mirad, los medios persiguen ganancias. Es legítimo ver esta historia como una nueva noticia. Yo creo que es decisión de los medios decidir cómo quieren cubrir las cosas” (Hirschfeld, 2015). 


\section{Metodología}

Teniendo en cuenta el objeto de estudio, los discursos sobre el ISIS de los candidatos presidenciales Trump y Clinton en Estados Unidos, como metodología se ha optado por un análisis cualitativo, longitudinal, basado en el análisis del discurso. Como apunta Van Dijk (1999: 66) "el análisis de discurso permite un conocimiento más detallado de los procesos discursivos de la agenda de discusión, las relaciones entre la política, los medios y la opinión pública”.

Van Dijk (1999: 9) distingue las diferentes formas en las que se ha abordado el análisis del discurso político. Desde el enfoque de los lingüistas (Chilton, 1985, 1988; Geis, 1987; Wilson, 1990; Wodak \& Menz, 1990), al de la retórica y la comunicación política (Bitzer, 1981; Chaffee, 1975; Graber, 1981; Swanson \& Nimmo, 1990). Pero en su opinión "sólo algunos de estos enfoques se han orientado, recientemente, al modo analítico del discurso (Van Dijk 1999: 9), al análisis crítico del discurso que reflexiona también sobre el contexto y la ideología como apuntan diversos autores (Van Dijk, 2002; Wodak, 2003; Laborda Gil, 2012; Pardo Abril, 2013).

El proceso de análisis del discurso seguiría estos pasos para Rodrigo-Mendizábal (1999: 103): "La primera parte del análisis es sobre todo descriptivo. De lo descriptivo se pasa a la parte connotativa, al significado de lo que se expresa. Estos dos pilares nos ayudan a situar el contexto del discurso y a partir de ellos, la propia dimensión discursiva del objeto analizado".

El análisis propuesto es una comparativa de las representaciones discursivas de cada candidato a través de su reflejo en la agenda de los medios, centrando la atención en dos aspectos: enfoque retórico, estrategias discursivas de los candidatos en sus declaraciones y enfoque lingüístico, lenguaje empleado para referirse a ISIS, sin olvidar el contexto del discurso y la ideología.

Además, antes del inicio del análisis, con la ayuda de la aplicación Textalyser, que crea nubes de palabras recogiendo aquellas que se repiten con mayor frecuencia, se crearon nubes de cada noticia, como primera aproximación a los temas, y palabras predominantes en cada uno de los discursos publicados por los medios.

- Enfoque retórico: estrategias discursivas

En esta categoría se determinará si los discursos son argumentativos, apelativos, incitan al miedo o predominan en ellos características propias de intervenciones populistas. Autores como Denton y Woodward (1998:5) consideran que "el lenguaje político puede servir para: argumentar y persuadir, establecer mecanismos de identificación y refuerzo, dotar de dramatización el discurso o crear etiquetas". Se estudiará si los candidatos desarrollan las siguientes estrategias:

- Provocación: captar atención receptor

- Apelación: involucrar al receptor en el sistema de valores que defiende

- Intimidación: para disuadir al receptor de una opinión distinta. Discurso del miedo.

- Argumentación 
Por otra parte, para detectar si los discursos tienen tintes populistas se analizarán, siguiendo la definición que hace Laborda (2012), los siguientes puntos:

- Se identifica a un enemigo

- Se apela a un pueblo opuesto a ese enemigo

- Se construye un líder hecho desde abajo y poseedor de grandes cualidades que lo legitiman como mejor conductor del pueblo y único salvador.

- Enfoque lingüístico: lenguaje

El filólogo Victor Klemperer (2014) destaca la importancia que tienen las palabras en el discurso político y avisa de que "Las palabras pueden actuar como dosis ínfimas de arsénico: uno las traga sin darse cuenta, parecen no surtir efecto alguno, y al cabo de un tiempo se produce el efecto tóxico" (Klemperer, 2014:31). Así, en este apartado se tendrá en cuenta los términos empleados y la relación existente entre ellos:

- Cuáles son las palabras más repetidas por los candidatos.

- Si se identifica a ISIS con ciertos temas como, por ejemplo, el terrorismo.

- Referencias a subtemas: refugiados, guerra, Siria, comunidad musulmana americana.

Este trabajo tiene como marco temporal los discursos e intervenciones sobre el ISIS recogidos por medios digitales norteamericanos (periódicos y webs de cadenas de televisión) entre noviembre de 2015 y febrero de 2016. Se trata de un periodo de algo más de tres meses que se ha elegido debido al hecho de que los atentados de París (13 de noviembre 2015) y los ataques de San Bernardino (2 de diciembre de 2015) tuvieron un fuerte impacto en la percepción de la amenaza terrorista entre la opinión pública norteamericana, según publicó Gallup, y se convirtió en el principal tema de política exterior de la campaña.

En cuanto a la muestra, tras una primera fase de investigación sobre todo el material publicado en esas fechas con un resultado de más de 60 publicaciones, se redujo la muestra final a 20 discursos, los más significativos relacionados con el ISIS:10 de Donald Trump y 10 de Hillary Clinton. Se trata de una muestra teórica, consistente como apunta Stubbs (1987: 224) en "escoger deliberada y explícitamente una muestra que pueda proporcionarnos datos especiales sobre lo que deseamos estudiar. Supone la búsqueda de personas y situaciones [o relatos ya conocidos] que puedan ser especialmente relevantes". Se tuvieron en cuenta las noticias con mayor extensión, en torno a fechas de acontecimientos que hubieran generado un mayor debate sobre el objeto de estudio y que mostrasen diversidad longitudinal del periodo analizado.

A continuación se presenta la relación medio-fecha de las informaciones utilizadas. 
Cuadro 1. Publicaciones analizadas

\begin{tabular}{|l|l|}
\hline DONALD TRUMP & HILLARY CLINTON \\
\hline THE NEWYORK TIMES $16 / 11 / 15$ & CNN4/11/15 \\
\hline THE HILL $L^{2} 19 / 11 / 15$ & CNN 15/11/15 \\
\hline CNBC $25 / 11 / 15$ & CBS $17 / 11 / 15$ \\
\hline CNN $3 / 12 / 15$ & CBS 19/11/15 \\
\hline CNN $8 / 12 / 15$ & CBS $3 / 12 / 15$ \\
\hline CNN $13 / 12 / 15$ & ABC NEWS $6 / 12 / 15$ \\
\hline CNN3/1/15 & NBC NEWS $15 / 12 / 15$ \\
\hline NBC NEWS $9 / 1 / 2016$ & ABC $19 / 12 / 15$ \\
\hline THE HILL 08/2/16 & CBN30/12/15 \\
\hline THE WASHINGTON POST 17/2/16 & BUSSINESS INSIDER 26/1/16 \\
\hline
\end{tabular}

Fuente: Elaboración propia

Los medios analizados incluyen sobre todo webs de cadenas de televisión, en especial aquellas que dieron una mayor cobertura a la campaña presidencial, dos medios especializados y los dos periódicos más importantes de Estados Unidos. Se tuvo en cuenta también que la muestra tuviese diversidad ideológica (ver anexo 1).

\section{Resultados de la investigación}

\subsection{Análisis del discurso de Donald Trump sobre ISIS}

Tres días después de los atentados de París (13-11-2015) el diario The New York Times recogía en un artículo titulado "Donald Trump Repeats Call To Inspect Mosques for Signs of Terrorism" la llamada de Donald Trump a "inspeccionar y cerrar las mezquitas", porque según el candidato republicano "algunas de las ideas de los terroristas y del odio viene de estos lugares".

2 The Hill es un periódico especializado en información política, congreso y campañas electorales. 


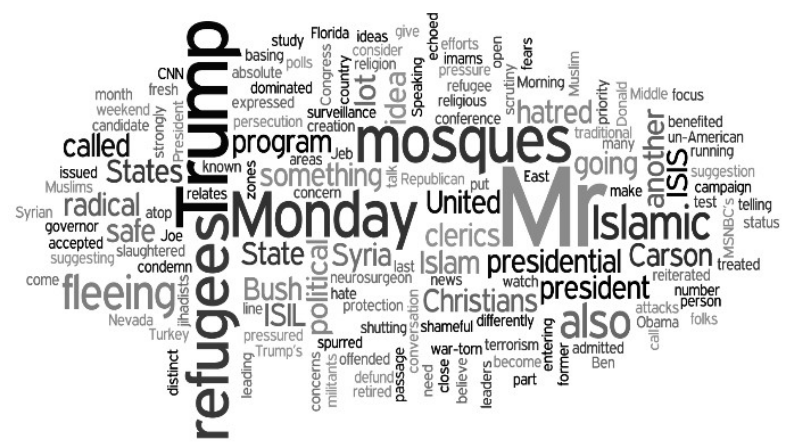

El discurso identifica un enemigo, ISIS. Apela al electorado indeciso justificando la inspección y cierre de mezquitas, que, aunque asegura "odia hacerlo" en las mezquitas se "habla demasiado". Recurre a la retórica del miedo y se identifica como salvador "del pueblo", como mejor candidato a la presidencia estadounidense. Entre las palabras más usadas, como puede verse en la nube de la imagen superior, están: Trump, refugiados, mezquitas, islámicos, ISIS, radicales y seguridad. Trata el subtema de la comunidad musulmana americana y los refugiados, sobre los que siembra la duda, y no diferencia entre radicales y los que no lo son. Identifica las mezquitas como uno de los focos de reclutamiento del grupo terrorista ISIS.

El periódico The Hill, especializado en información política y campañas presidenciales, recoge en su artículo de 19 de noviembre de 2015 titulado “Trump: I Would “Absolutely” Use Databasa to Track Muslims” las consideraciones que Trump realizó sobre los musulmanes, llamándolos entre otras cosas “caballos de Troya”.

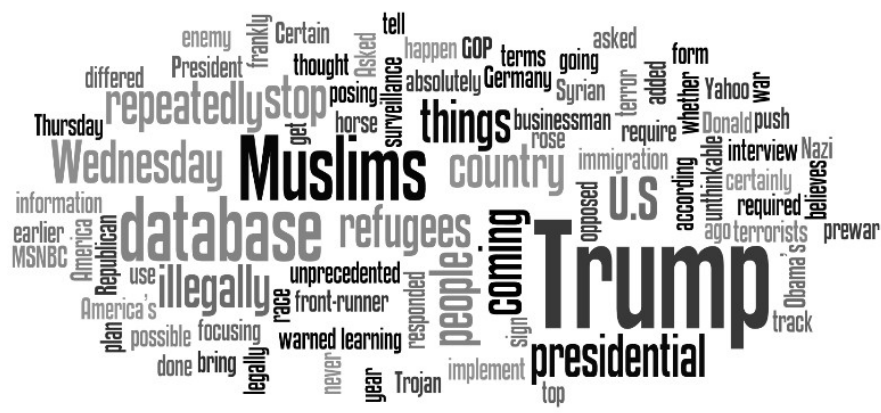

Su estrategia es intimidar e instaurar el miedo diciendo que los refugiados pueden ser terroristas, llamándolos "caballos de Troya" que usan esta excusa para entrar en América. Para acabar con esto Trump dice que va a aplicar una vigilancia sin precedentes que incluye también a los "musulmanes americanos". Se opone una vez más a la idea de Obama de alojar a 10.000 refugiados sirios en el país. 
Además, aboga por la creación de una base de datos de musulmanes que acabaría con la inmigración ilegal. Musulmanes, Trump, base de datos, refugiados, son en este caso las palabras más destacadas, como puede verse en la nube de la imagen superior.

La $C N B C$, el 25 de noviembre, publica la intervención de Trump en Carolina del Sur, "Donald Trump Says He Can Predict Terrorism: "I Can Feel It", en la que manifestaba ser capaz de "sentir el terrorismo" y de "predecirlo", algo que lo ayudaría para hacer "America Great Again”, el lema principal de su campaña.

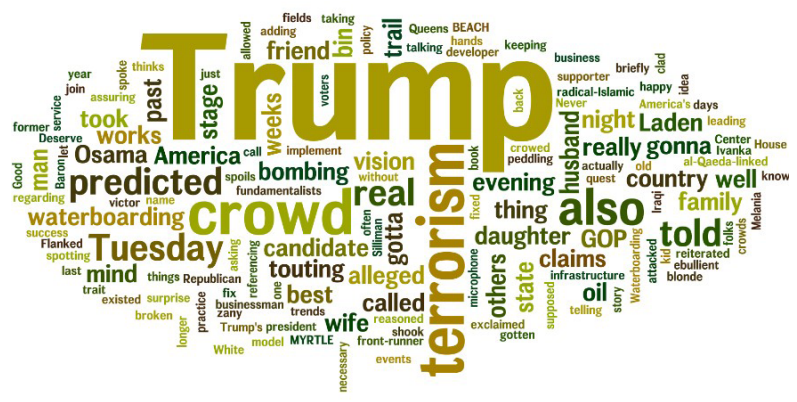

Provoca diciendo que "puede sentir el terrorismo" algo poco creíble que él respalda, según cuenta el medio, con una "elaborada y larga historia". Apela a las emociones y al sentimiento de grupo. Habla de la nación y los valores americanos como opuestos a ISIS y se postula como el único capaz de salvar esta situación, por ser el único que tiene la habilidad de "predecir el terrorismo".

Intenta ganar adeptos para la causa, porque va a arreglar "nuestro país, que está roto", refiriéndose a Estados Unidos. Las palabras más utilizadas, como puede verse en la nube de la imagen superior fueron Trump, terrorismo, predecir, multitud y Osama. Se atribuye la cualidad divina de poder "predecir" cosas. Habla de "arreglar" y "reconstruir" América que está "rota". Empatiza con su auditorio al que se dirige como "folks" y les hace sentir parte del grupo en las intervenciones de la familia de Trump.

La $C N N$ recoge el 3 de diciembre las declaraciones de Trump en las que propone como parte de su estrategia para terminar con el ISIS "matar a la familia de los terroristas" para ganar la lucha contra este grupo: "Donald Trump on Terrorists: "Take Out Their Families”. 


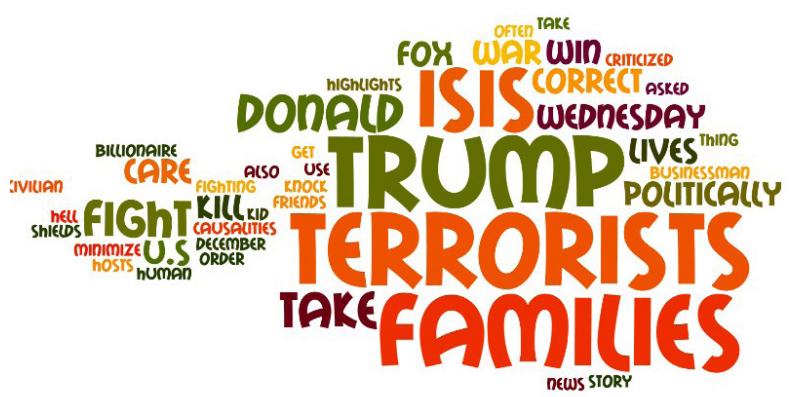

Trump apela al miedo del auditorio para convencerles de que hay que usar la fuerza porque América ha sido atacada. "Una vez que tienes a los terroristas, tienes que coger a sus familias. Cuando ellos no se preocupan por su propia vida hay que ir por la de sus familiares”, aseguró. También criticó a los Estados Unidos por estar siendo demasiado “correctos políticamente”. Se muestra de nuevo como el hombre que tiene la solución, el salvador. ISIS, Trump, terroristas, familia, matar y lucha son, en esta intervención, las palabras que más se pronuncian, como puede verse en la nube de la imagen superior. Usa la expresión “mandar al infierno al ISIS”, un término relacionado con la religión.

La CNN recoge en el artículo del 8 de diciembre la intervención en la que Trump reiteró su idea de prohibir la entrada a los musulmanes y los argumentos que empleó para justificarse. Trump aseguró que podía haber más ataques como el 11S: “Trump Warns: Many More World Trade Centers”.

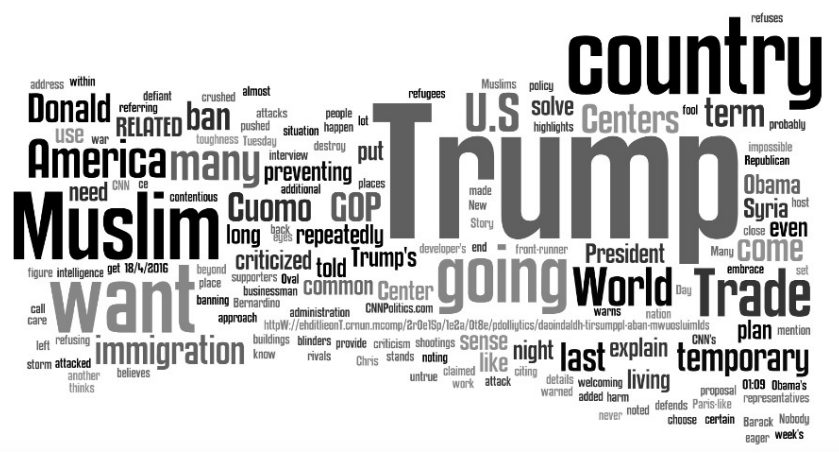

En este discurso sigue una estrategia de apelación e intimidación, con un tono que el medio califica de “desafiante”. Intenta instaurar el miedo entre el auditorio recordando uno de los hechos más traumáticos que ha vivido el país, el 11 S. Dice el candidato que "si no se para la entrada de inmigrantes musulmanes en Estados Unidos, habrá muchos más ataques como los del 11S”. Además, el candidato se distancia de sus contrincantes, incluso de la línea de su partido y dice que 
"no le importa lo que digan los Republicanos sobre su plan de prohibir la entrada a los musulmanes". No deja claro por cuánto tiempo ni da detalles sobre la prohibición. Trump critica la gestión del conflicto del actual presidente con frases como esta: "Barack Obama no acepta que estamos en guerra contra el terrorismo islámico radical", que recuerdan el frame de "guerra contra el terror" utilizado por la Administración de Bush. Lenguaje discriminatorio y racista. País, América, musulmanes, inmigración, prohibir, se encuentran entre las palabras más destacadas.

En el artículo de la CNN el 13 de diciembre, -“Trump: My Muslim Friends Don’t Support My Immigration Ban”-, recoge las declaraciones de Trump diciendo que "los amigos" que tiene dentro de la comunidad musulmana saben que "les estoy haciendo un favor".

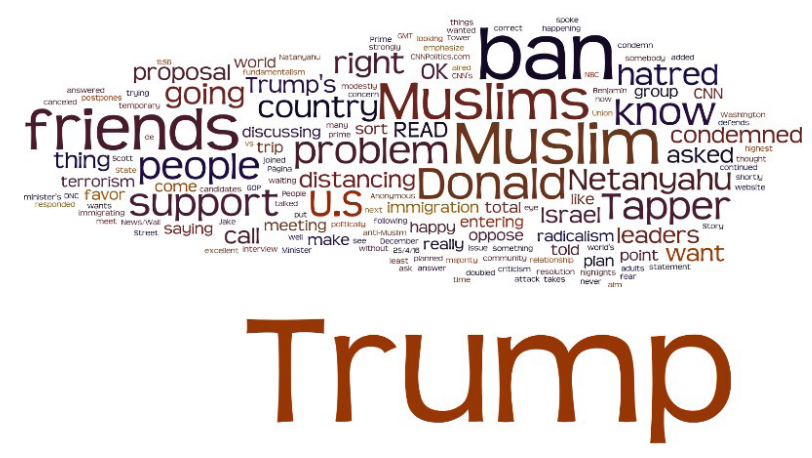

También intenta intimidar e instaurar miedo con frases como "Vosotros tenéis radicalismo en este país. Los terroristas le tienen "total odio" a Estados Unidos: “tenemos que saber la respuesta o no estaremos nunca seguros”, añade. Se postula como el salvador, se construye como líder. "No soy políticamente correcto, pero estoy haciendo las cosas que hay que hacer. Soy candidato para hacer las cosas correctas". Musulmán, musulmanes, prohibir, amigos, problema, país, son las palabras más destacadas, como puede verse en la nube de la imagen superior. Subtemas como el de los refugiados que relaciona directamente con el grupo armado, como potenciales terroristas que quieren "hacer caer sus ciudades".

La $C N N$ incluye información que dejaba patente que la medida de prohibir la entrada a Estados Unidos a los inmigrantes era rechazada por la mayoría de la sociedad americana.

La noticia del 3 de enero de la $C N N$ recoge una de las acusaciones más fuertes del multimillonario al presidente del gobierno, Obama, y a la candidata a la Casa Blanca, Hillary Clinton, que en su momento fue Secretaria de Estado de Obama. El titular: “Trump: Clinton, Obama Created ISIS”. “Clinton y Obama crearon el ISIS”, afirma el provocador Trump. 


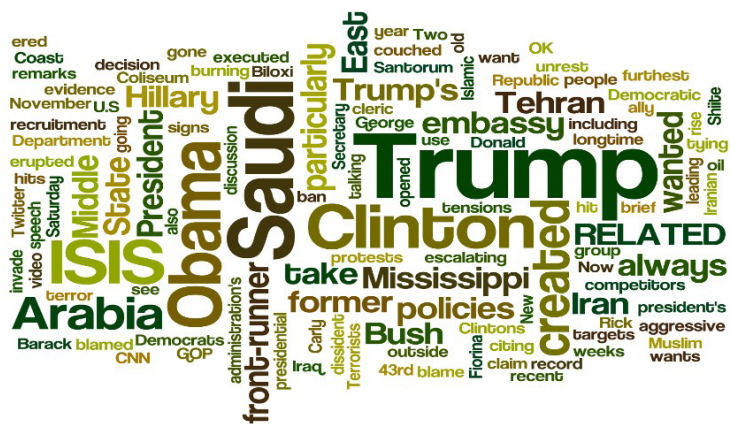

Está intentando ganar indecisos y reforzar a sus votantes. Identifica al enemigo ISIS, pero también son enemigos Obama y Clinton cuya política exterior es responsable de la situación por "haber ayudado al crecimiento del grupo terrorista". También acusa al ex presidente George W. Bush, republicano, de una mala gestión y arremete especialmente contra la decisión de invadir Irak en 2003. En esta ocasión Trump utiliza de nuevo un lenguaje ofensivo y relaciona directamente a los terroristas con los demócratas. Se presenta como el candidato que ha llegado para solucionar todo. El medio aclara que "Trump no ofreció ninguna evidencia para sus acusaciones".

La cadena televisiva NBC NEWS se refiere al discurso de Trump comparando a los refugiados sirios con el ISIS, mientras que su acto era interrumpido por una mujer musulmana el 9 de enero. "Trump Tells Rally Syria Refugees “Probably” ISIS as Muslim Protester Removed".

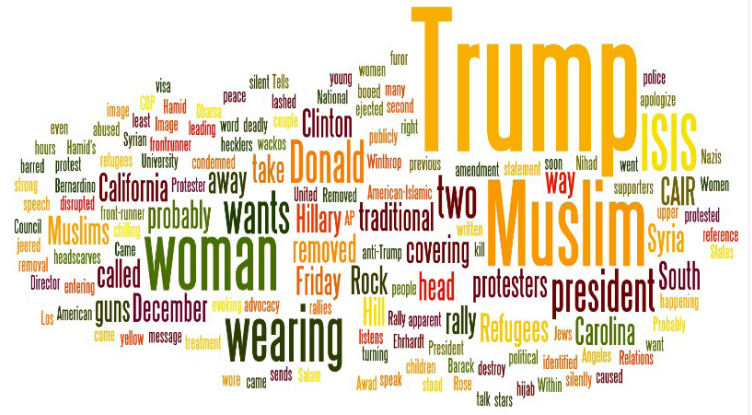

El medio destaca las interrupciones y protestas que hubo durante el acto. Retórica del miedo: alarma diciendo que la gente que viene de Siria, escapando de la guerra, pueden ser terroristas e intimida hablando sobre las consecuencias que puede traer acogerlos. Justifica sus acusaciones con frases como "Son muchos hombres, todos jóvenes y fuertes” y acto seguido habla sobre la matanza de San Bernardino. Introduce además el tema del debate de las armas: "Clinton os quiere quitar las armas", hace entender a su público que las armas son necesarias para defenderse. Trump, mujer, musulmán, ISIS y Siria son algunas de las palabras más destacadas, como puede verse en la nube de la imagen superior. 
The Hill recoge el 8 de febrero unas declaraciones de Trump en New Hampshire en las que se mostró capaz de "mirar a los ojos" a un niño y decirle que "no puede entrar en Estados Unidos", cuando estaba teniendo lugar un debate sobre si vetar o no la entrada a los demandantes de asilo que provienen de Siria. "Trump to Syrian Refugee Children: "You can't Come Here”.

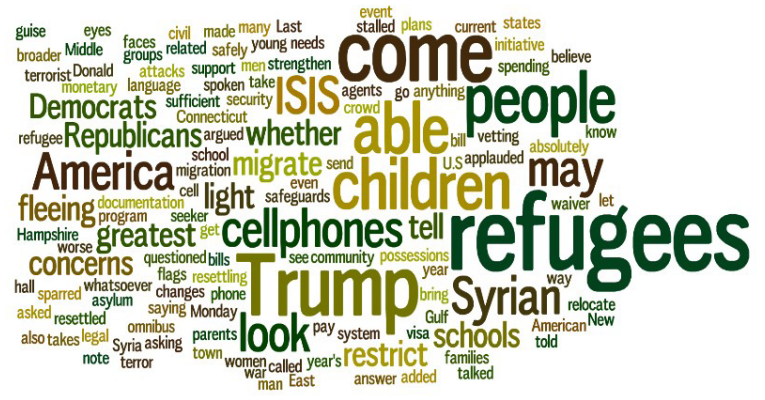

“Vosotros los veis con móviles -¿Dónde han conseguido sus móviles? Esto es una migración, ellos no tienen nada, pero tienen teléfonos con la bandera del ISIS y cosas aún peores". Frases discriminatorias y racistas que prácticamente inducen a pensar que los refugiados con móvil son militantes del ISIS. Se muestra como un gobernante firme capaz de hacer cualquier cosa por la seguridad de su país y sus ideas, incluso decirle a un niño que no puede entrar "mirándolo a los ojos". Respecto al lenguaje, establece una diferencia populista entre "ellos" y "nosotros". Refugiados, niños, ISIS, teléfonos, migrantes, sirios y América están entre los términos más usados, como puede verse en la nube superior.

En el reportaje del 17 de febrero The Washington Post hace un repaso de las intervenciones de Trump acerca de la técnica de tortura "waterboarding", a colación de un discurso del candidato a la Casa Blanca en la que asegura que "nadie puede decir que la tortura no funciona”. El titular: “Trump Says “Torture Works”, Backs Waterboarding and "Much Worse”.

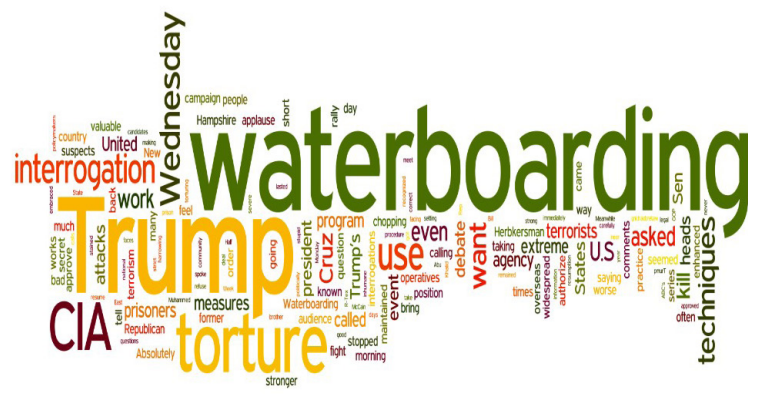

Apela al miedo al asegurar que los terroristas "van por ellos" y "que los quieren matar". "Quieren matarnos" asegura usando el "nosotros" en contra del "ellos". Lenguaje populista: "Ellos quieren matar nuestro país. Ellos quieren derrumbar nuestras ciudades". 
Como parte de la solución que propone para acabar con este peligro, es la vuelta a técnicas de tortura (prohibida por Obama en 2009) como el waterboarding3. "Si no funciona, ellos se lo merecen igualmente". Los términos que más se repiten son tortura, CIA, waterboarding, interrogatorio, técnicas, terroristas y Estados Unidos. Se postula como el candidato que puede hacer frente a este fuerte enemigo y pide al pueblo que le "crean" apelando a la fe en él, usando lenguaje religioso.

En resumen, todos los discursos de Trump siguen la misma línea en cuanto a estrategia. Apelan a los sentimientos de los ciudadanos estadounidenses e intentan intimidar al auditorio propagando el miedo y hablando sobre posibles amenazas. Crea preocupación y alarma diciendo que ya hay terroristas en el país, que se preparan en sus mezquitas, con un discurso islamófobo, que extiende de forma generalizada a los musulmanes y aquellos que están llegando como refugiados. Apuesta por una política de mano dura en la que habla de volver a las técnicas de tortura, o el cierre de fronteras.

Una vez que tiene a su público convencido de que algo malo va a pasar, se postula como el único líder capaz de evitarlo. Para esto descalifica a sus contrincantes con lo que haga falta, incluyendo la acusación de relación de los demócratas con el grupo terrorista ISIS. Usa un tono populista en sus discursos, en los que siempre hay un "nosotros" y un "ellos". Utiliza el pasado doloroso y evoca recuerdos trágicos como el del 11-S para apelar a sus sentimientos o emplea frases como "los viejos tiempos en los que América era grande".

A través de preguntas retóricas, el lenguaje de Trump no solo relaciona al ISIS con la violencia y el peligro, sino que dentro de ese enemigo que es ISIS incluye a todos los refugiados sirios y seguidores del Islam, ya sean extranjeros o pertenezcan a la comunidad musulmana americana. Además, el candidato republicano utiliza términos religiosos, apela a que se "crea en él", habla del "infierno". Se atribuye cualidades divinas como la de "poder predecir el terrorismo" y se postula como salvador de América.

Cuadro 2. Subtemas en los discursos de Trump sobre ISIS

\begin{tabular}{|l|}
\hline SUBTEMAS \\
\hline REFUGIADOS SIRIOS \\
FAMILIAS DE LOS TERRORISTAS \\
$11 S$ \\
OBAMA \\
TORTURA \\
WATERBOARDING \\
SAN BERNARDINO \\
\hline
\end{tabular}

Fuente: Elaboración propia

3 Consiste en ahogar al interrogado con una bolsa de plástico en su cabeza -si es la manera seca- y si no en meter la cabeza del susodicho en un tanque con agua salada, orina u otras substancias. 
La $C N N$ es el medio que más abiertamente se mostró en contra del multimillonario y se hizo eco de encuestas que desmentían lo que decía el candidato.

\subsection{Análisis del discurso de Hillary Clinton sobre ISIS}

La CNN recoge el 4 de noviembre la respuesta de Clinton en el ayuntamiento de Coralville a la pregunta de qué podría hacer Estados Unidos por la crisis de refugiados en Siria y África. El titular es "Hillary Clinton: Climate Change Has Contributed To Refugee Crisis, Including Syria".

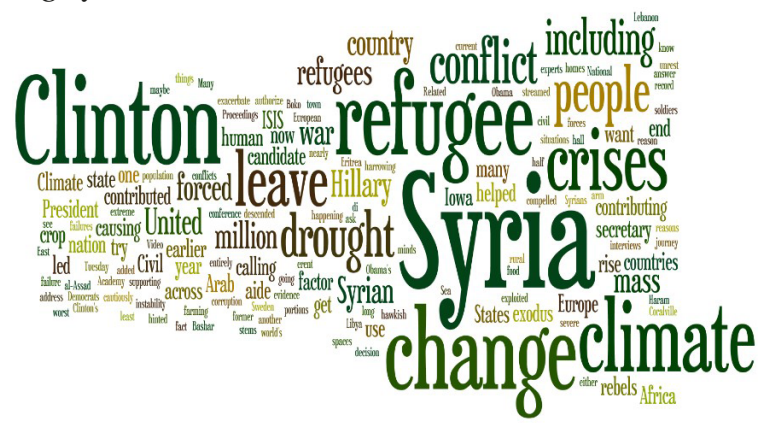

Llama, apela para que sus seguidores se pongan en la piel de los refugiados. Defiende una postura activa de Estados Unidos en Siria, argumentado que si Estados Unidos resuelve los problemas de Siria no habrá más refugiados pidiendo asilo. Refugiados, Siria, cambio climático, conflicto, gente y crisis son términos destacados, como puede verse en la imagen superior. El medio asegura que Clinton "ha sido la más militante de los demócratas en el tema de Siria, apelando por una zona segura en Siria y apoyando de manera cautelosa la medida de Obama de usar las fuerzas especiales en Siria".

La $C N N$ el 15 de noviembre se refiere al debate demócrata que tuvo lugar dos días después de los atentados de París, y en que la candidata Clinton abogó por "unir al mundo" en la lucha contra los yihadistas radicales. Titular: "Clinton Calls Out Radical Jihadist Ideology".

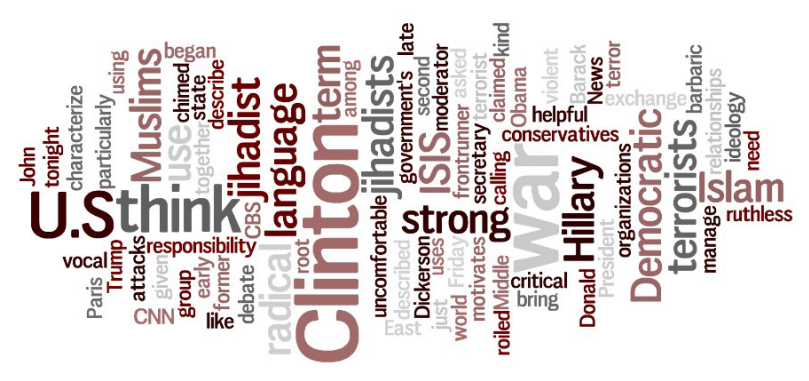


Hace especial hincapié en el lenguaje. Apela a la ciudadanía para llevar a cabo una lucha pacífica, con mucho cuidado de no comparar a los terroristas con los seguidores del Islam. Identifica un enemigo: sí "el yihadismo". De hecho, dice "No creo que estemos en guerra con el Islam, no pienso que estemos en guerra con los musulmanes, estamos en guerra con los yihadistas". Describe al ISIS como barbarie, violentos, yihadistas y grupo de terroristas. Guerra, yihadistas, musulmanes, islam, lenguaje, pensar, Estados Unidos, son las palabras más subrayadas por la demócrata.

La CBS NEWS difunde el 17 de noviembre las declaraciones de Clinton en un mitin en Dallas, en las que explica su posición respecto a la decisión de Obama de acoger a refugiados y el escándalo generado por los republicanos por ser reticentes a esta idea. Titular: "Hillary Clinton Weighs In On Syrian Refugee Crisis".

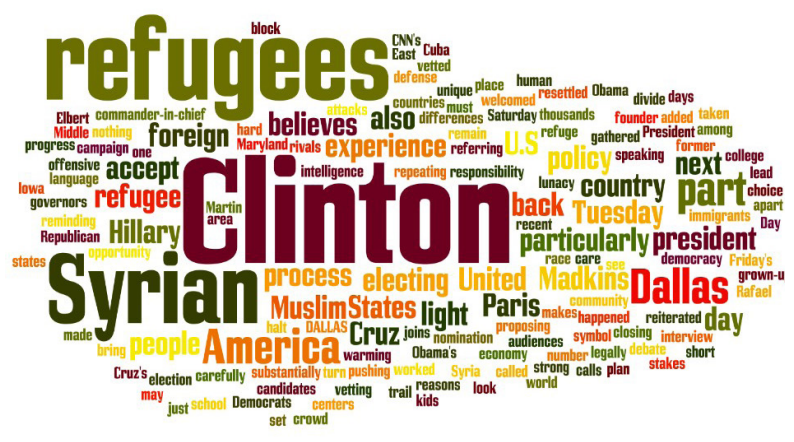

Apela en su estrategia al sentimiento de América como nación. Cerrar la puerta a los refugiados que escapan de Siria no representa para Clinton "lo que somos como americanos", perjudica la imagen ya que en Estados Unidos "siempre han sido bienvenidos los inmigrantes y los refugiados". En este discurso también critica la retórica de Trump, que según la candidata incita al odio. Además, se postula como la candidata que va a mantener América unida con una serie de valores, frente a Trump, a quien acusa de estar dividiendo Estados Unidos. Sirios, refugiados, América, París, extranjero, son los términos más destacados en esta ocasión, como se observa en la imagen superior.

Poco después de los atentados de París del 13 de noviembre de 2015, la candidata Hillary Clinton dio un discurso con posibles medidas que tomará respecto a ISIS si llega a la presidencia estadounidense. Titular en CBS NEWS del 19 de noviembre: "Hillary Clinton to Outline Strategy to Defeat ISIS After Paris Attacks". 


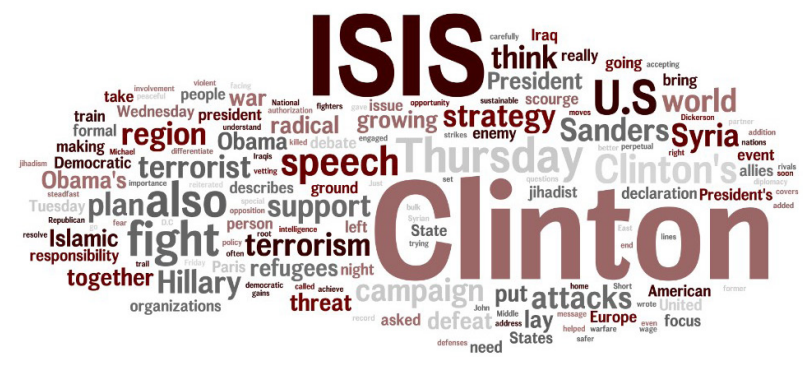

"Desmantelar la amplia infraestructura que usa la organización terrorista para entrenar a sus militantes y extender su mensaje, mejorar la fuerza de EE.UU. y sus aliados y ayudar por vía aérea con los servicios de inteligencia”, son las medidas de Clinton para acabar con ISIS. Además, aseguró que hay que acabar con la financiación del grupo y crear una zona segura sin bombardeos en Siria.

Identifica un enemigo, el ISIS, un "ellos" los terroristas y un "nosotros" que sería América y sus aliados. No menciona a los musulmanes y para referirse a los miembros del grupo los llama yihadistas radicales. Respecto al tema de los refugiados, la candidata no solo ha aceptado la iniciativa de Obama de acogerlos, sino que ha propuesto una cifra mucho mayor de personas que hay que acoger. ISIS, lucha, terrorismo, Siria, Sanders, ataque y lucha son palabras destacadas. Clinton habla de yihadismo radical o de terrorismo del islamismo radical, y no generaliza con los musulmanes

El 3 de diciembre Clinton reconoce que la matanza de San Bernardino está relacionada con el terrorismo. Titular de la CBS NEWS: "Hillary Clinton: Be Coming Clear San Berdardino Shooting "Act of Terrorism" (Hillary Clinton es clara sobre el tiroteo de San Bernardino, un "acto terrorista").

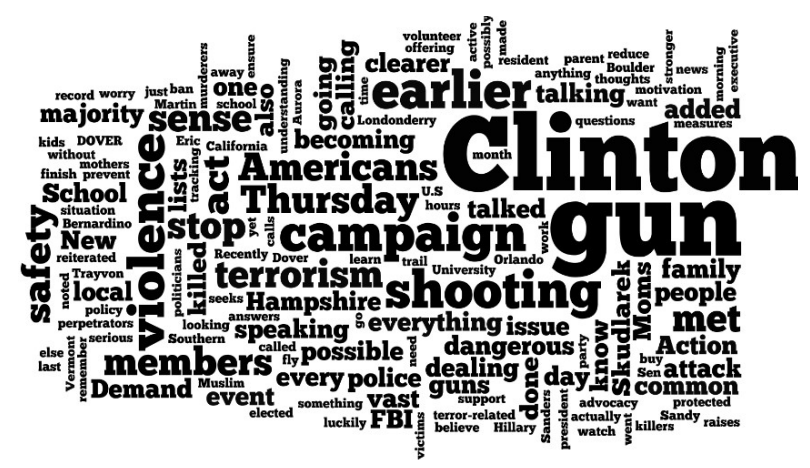


Llama a la calma y pide a los ciudadanos que no tengan miedo, apela a su sentimiento de libertad. "Nadie debería tener la percepción de que se le ha robado su seguridad" y apela al "sentido común" para pedir una regulación de ventas de armas en el país, intenta que los ciudadanos confíen en las fuerzas de seguridad y en la nación y no se tomen la fuerza por su cuenta. Arma, violencia, americanos, campaña, terrorismo, disparos y seguridad son palabras muy presentes en el texto. Diferencia entre los musulmanes americanos y los terroristas. "La mayoría de los musulmanes americanos están más concienciados que nadie y son los que más roto tienen el corazón”.

La $A B C N E W S$ se refiere, el 6 de diciembre, al discurso de Clinton sobre posibles soluciones para terminar con potenciales aliados al ISIS, como los asesinos de San Bernardino a los que llama wannabes-aspirantes-. Titular: "Hillary Clinton Calls San Bernardino Shooting Suspects ISIS “Wannabes”.

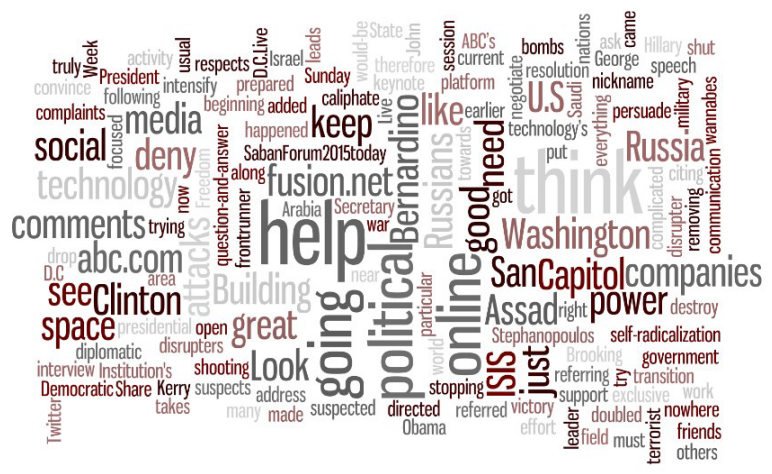

La estrategia pasa, para Clinton, por un mayor control de Internet para limitar la oportunidad de este grupo de disfrutar de plataformas de comunicación abiertas. Clinton intenta convencer al público sobre la necesidad de recortas algunas libertades. Si se toman medidas de este tipo "escucharéis las quejas de siempre" sobre la "libertad de expresión" pero si realmente "estamos en una guerra contra el terrorismo de verdad, tenemos que cortarles el grifo de su financiación y frenar que se sigan alistando a sus filas militantes extranjeros".

Apela a la seguridad, y en este caso utiliza el discurso del miedo asegurando que, si no se aplican medidas como ésta, no se va a poder acabar con el ISIS, que es el enemigo. El papel de los Estados Unidos es intensificar su política diplomática, asegura, y tienen que convencer a Rusia para que les ayuden a luchar contra el ISIS. Ayuda, políticos, San Bernardino, Capitolio, compañías, ISIS, Washington son términos subrayados en esta intervención, como muestra la nube de la imagen superior. En este caso la candidata reconoce estar "guerra contra el terrorismo".

El reportaje de la $N B C$ del 15 de diciembre recoge las declaraciones de Clinton en Minneapolis y hace un repaso sobre el plan de política exterior que propuso la candidata respecto al ISIS y los refugiados. Titular: "Hillary Clinton Unveils Plan to Stop Spread of ISIS" (Hillary Clinton desvela su plan para frenar el crecimiento del ISIS). 


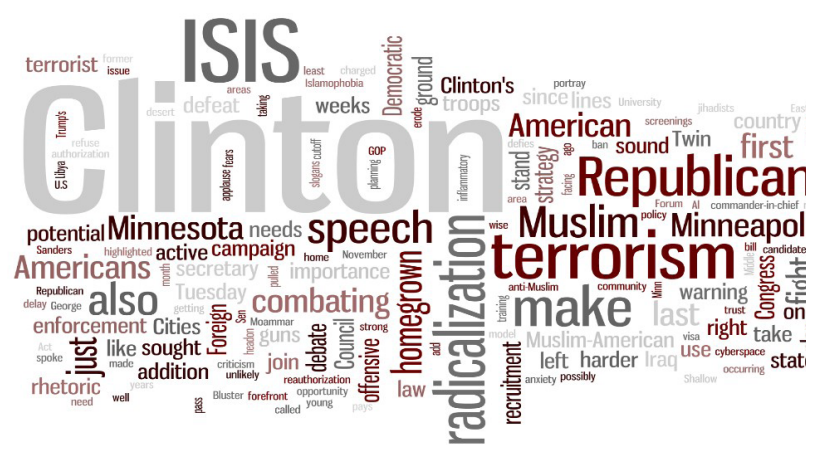

El plan estaba motivado por los atentados de París y el de San Bernardino. Es el tercer discurso que la candidata pronuncia sobre el ISIS en menos de un mes. Muestra cómo Clinton reitera la idea de que la islamofobia no es buena y puede ser incluso "perjudicial" para América.

Clinton identifica al ISIS como enemigo. Llama la atención del auditorio sobre el país, porque está en alerta y conflicto. Reconoce que los americanos están en "su derecho de tener miedo" pero ataca a aquellos que "solo usan eslóganes sin una estrategia o se aprovechan de este miedo para hacer campaña", en clara referencia a los republicanos, aunque Clinton no llega a nombrarlos.

Se postula ella como líder de una "estrategia de 360 grados" que mantendrá a América a salvo. Acabar con la financiación del ISIS, combatir su reclutamiento online o vigilar de cerca de los viajeros que hayan estado en los últimos cinco años en países que tengan que ver con el ISIS son algunas de las medidas que Clinton ofreció. Una vez más subrayó lo importante que es tener claro que la comunidad americana musulmana no es parte del problema, sino que lo es de la solución. Asegura que la islamofobia que se estaba dando en los últimos días era "ofensiva" y dañina para la Seguridad Nacional. ISIS, radicalización, terrorismo, republicanos, América, discurso, combatir e islamofobia son algunos de los términos destacados de esta noticia. Califica a la retórica republicana "anti musulmana” y la vincula con el odio.

El 19 de diciembre la $A B C$ recoge las declaraciones de Clinton durante el debate demócrata que tuvo lugar en la misma cadena. Titular: "Hillary Clinton Says Trump is “Becoming ISIS’s Best Recruiter”" (Hillary Clinton dice que Trump se está convirtiendo en el mejor reclutador que tiene el ISIS). 


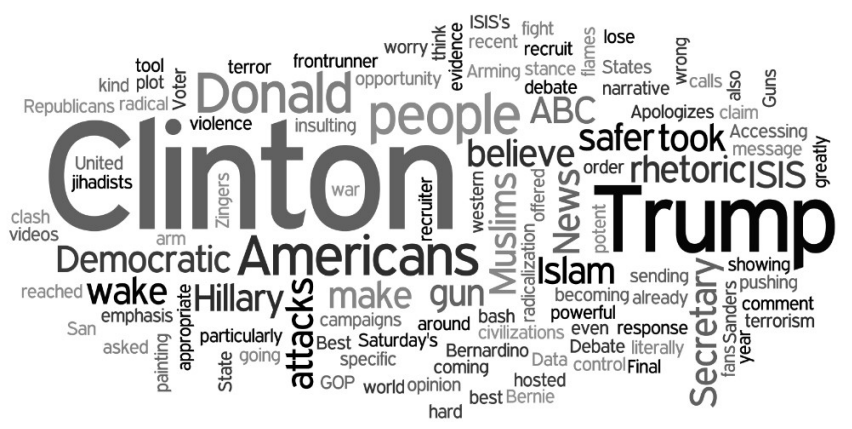

Utiliza a un enemigo común de todos los americanos, el ISIS, para atacar a su contrincante, Trump. En su discurso hace al republicano parte del problema que tiene que enfrentar ahora Estados Unidos. "Él está siendo el mejor reclutador del ISIS. Ellos están enseñando a la gente vídeos de Trump insultando al Islam y a los Musulmanes para reclutar a más yihadistas radicales". También aprovecha para decir que el tener armas no hace "estar más seguros a los americanos". Clinton se postula como la solución que necesita América. Trump, americanos, gente, ataque, armas, Islam, ataques, yihadistas son algunos de los términos más reseñables de esta intervención. Clinton tilda a Trump de "instrumento potente y poderoso" del ISIS.

CBS NEWS refiere, el 30 de diciembre, el duro ataque verbal de Clinton a ISIS. Titular: "Hillary Clinton Now Says ISIS is Committing ‘Genocide” (Hillary Clinton ahora dice que ISIS está cometiendo genocidio).

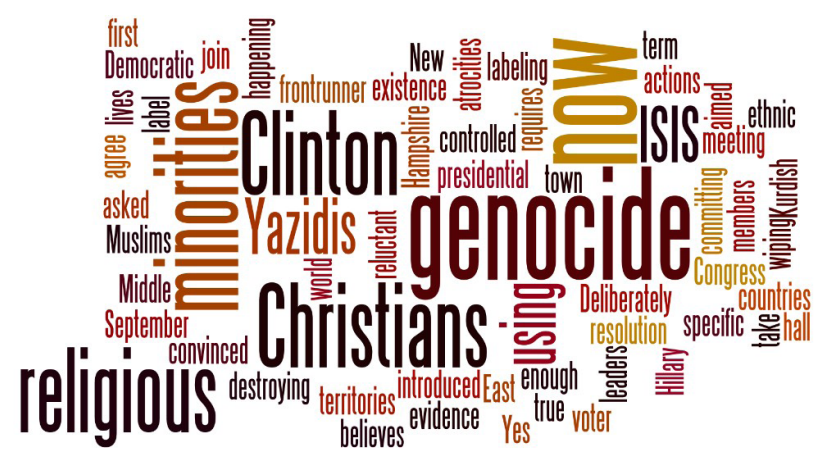

Utiliza la estrategia del miedo frente a un enemigo genocida, ya no solo para los americanos o en Siria, sino para los seguidores de otras religiones. "Lo que está pasando es genocidio. El objetivo que tienen es no solo destruir nuestras vidas también acabar con la existencia de los cristianos y otras minorías religiosas en el Medio Oriente, en territorios controla- 
dos con el ISIS". Genocidio, cristianos, religiosos, minorías e ISIS son los términos más repetidos en esta noticia. Clinton relaciona la etiqueta de "genocidio" directamente con el ISIS.

Business Insider publicó el 26 de enero la respuesta de Clinton a una veterana de las fuerzas aéreas de Estados Unidos sobre la islamofobia. Titular: "Hillary Clinton Responded To a Muslim Veteran's Question on Islamophobia With a Scathing Criticism of Donald Trump". (Hillary Cinton responde a una veterana musulmana sobre la islamofobia con una crítica a Donald Trump).

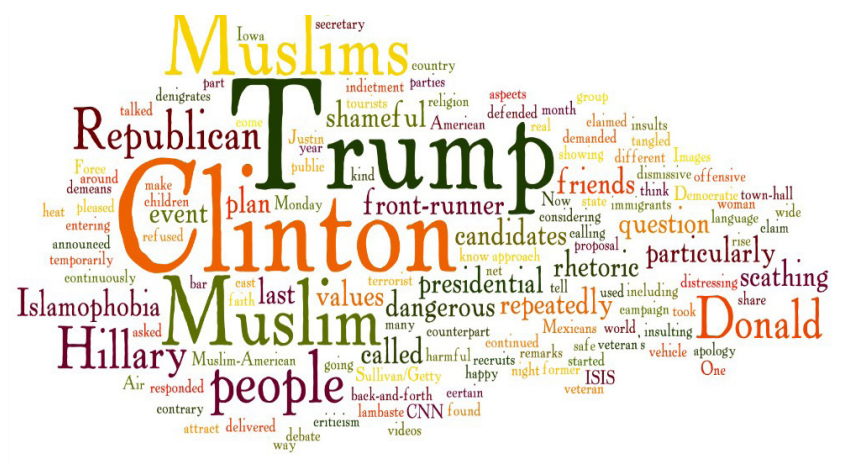

Clinton calificó como "peligroso" a Trump. Señaló que una de las peores cosas de la campaña actual era la retórica de los republicanos y el uso de insultos que denigran a la gente. Se postuló como la líder capaz de gobernar para todos y acabar con un problema. Dañino, peligroso, vergonzoso y contrario a los valores americanos, así valora Clinton el discurso de Trump, además de identificarlo con la violencia y la islamofobia.

Resumiendo, los discursos de Clinton tienden a ofrecer medidas concretas para acabar con el ISIS si llega a la presidencia de los Estados Unidos y no tanto declaraciones impactantes y provocativas como Trump. Apela a los "valores americanos", y pide ayuda tanto a potencias internacionales como a empresas tecnológicas para acabar con la amenaza y actividad del ISIS, un enemigo con el que reconoce estar en "guerra". Acusa a Trump de ser parte del problema para acabar con ISIS y no parte de la solución. 
Cuadro 3. Subtemas en los discursos de Clinton sobre ISIS

\begin{tabular}{|l|}
\hline SUBTEMAS \\
\hline CAMBIO CLIMÁTICO \\
REFUGIADOS SIRIOS \\
PARÍS \\
SAN BERNARDINO \\
RUSIA \\
ISLAMOFOBIA \\
GENOCIDIO \\
\hline
\end{tabular}

Fuente: Elaboración propia

Aunque de manera menos repetitiva que los discursos de Trump, los de Clinton también tienen tintes populistas en cuanto a la presentación de su liderazgo como la única salida a la situación de Estados Unidos.

\section{Conclusiones}

La última campaña presidencial en Estados Unidos es un ejemplo más de cómo los políticos y el sistema mediático retroalimentan sus agendas. La difusión de imágenes y noticias relacionadas con el ISIS por parte de los medios, a raíz de hechos como los atentados de París o de San Bernardino, y encuestas como la de Gallup, que situaron el terrorismo como tema más importante para los americanos, condicionaron la agenda de los políticos que aumentaron sus discursos relacionados con el tema. Aunque hubo otros problemas de política exterior que salieron a la palestra en los debates entre republicanos y demócratas, como la inmigración mexicana o Irán, el ISIS y sus subtemas fueron uno de los grandes protagonistas de la campaña.

A diferencia del 11S, en el que el frame de "guerra contra el terror" consiguió un elevado consenso entre el discurso de los medios y de los políticos, en esta campaña el frame de la guerra contra el terrorismo de ISIS no logró ese consenso, como se ha visto en el caso de algunos medios analizados que cuestionaron las propuestas de Trump.

Republicanos y demócratas construyeron en sus discursos la figura del “otro", la amenaza de ISIS y cómo combatirla de manera muy diferente. El tono provocativo e intimidatorio de Trump contrastó con el discurso más argumentativo de Clinton, que no obstante, también enarboló en ciertos momentos la bandera del populismo. Las palabras y la retórica de los candidatos condicionaron el contexto en el que se desarrolló la campaña.

Los discursos de Trump pocas veces estuvieron exentos de conflicto y polémica, algo que, sumado a la actualidad e inmediatez, proporcionó a los periodistas ingredientes de noticia, en el sentido apuntado por Seymour-Ure (1974) o Canel 
(2006). El candidato republicano obtuvo así mayor repercusión mediática que todos los demás candidatos con sus declaraciones incendiarias, como la acusación a Obama y a Clinton de ser los creadores de ISIS.

Los tintes populistas de su discurso frente al ISIS, -que coinciden con las características apuntadas por Laclau (1977), Patriau (2012), Laborda (2012) - consistieron no solo en identificar a un enemigo y apelar al pueblo americano frente a ese enemigo, sino en presentarse como líder casi con cualidades divinas, único salvador posible de la nación.

Trump no tenía un plan claro para combatir el ISIS y apeló continuamente al miedo en sus discursos, incluso a la intimidación de su contrincante, y a la creación sistemática de etiquetas islamófobas, de "ellos", -el enemigo, el ISIS, pero entendido de una forma discriminatoria hacia toda la comunidad musulmana que nada tiene que ver con el grupo terrorista-, frente al "nosotros", la nación americana.

Mientras, Hillary Clinton intentó argumentar en la mayor parte de sus discursos las propuestas que planteaba con un tono más conciliador y respetuoso en el lenguaje, aunque utilizó también en ocasiones la fórmula populista de presentarse como la única salvadora de América. El plan frente al ISIS de Clinton trató de trasmitir un sentimiento de seguridad a los ciudadanos.

Los resultados de estas elecciones presidenciales han mostrado que tuvo éxito el llamado efecto priming (Iyengar y Kinder, 1987), -cuyo influencia es mayor en los ciudadanos con menor nivel de estudios-, que consiste en valorar a un político por lo que han recibido sobre él a través de los medios. La sobreexposición y aparición en medios de discursos cada vez más radicalizados de Trump contribuyó sin duda a ello.

\section{Referencias bibliográficas}

Abu-Warda, A. y Portaña, M. L. (2011): “Comunicación y política en la Casa Blanca: el conflicto de Iraq y su repercusión en la opinión pública de Estados Unidos y el mundo árabe”, Revista de Relaciones Internacionales de la UNAM, nº 109, enero-abril, pp. 113-132.

Alcácer, R. (2015): La protección de los Derechos Fundamentales en la extradición y la euroorden. Pamplona: Aranzadi.

Busso, A. (2002): "La política exterior estadounidense a partir de la administración de George W. Bush; su impacto mundial y regional”, en Guida, M. (2010): “La política exterior neoconservadora en Estados Unidos”, Revista CIDOB D'Afers Internacionals, no 91, pp. 197-220.

Canel, M. J. (2006): Comunicación Política. Guía para su estudio y práctica. Madrid: Tecnos.

Chomsky, N. (2003): Poder y terror: Reflexiones posteriores al 11/9/2001. Barcelona: RBA. 
Dearing, J. W. y Rogers, E. (1996): Agenda Setting. California: Sage Publications.

Denton, R. E. y Woodward, G. (1998): Political Communications in America. Praeger.

Entman, R. (1993): “Framing: toward clarification of a fractured paradigm”, Journal of Communication, nº 43, pp. 51-58.

Fairclough, N. y Wodak, R. (1997): “Critical Discourse analysis”, en Van Dijk, T. A. (2000) El discurso como interacción social. Estudio sobre el discurso II. Una introducción multidisciplinaria. Barcelona: Gedisa, pp. 467-404.

Fontecilla, M. E. (1988): “La ‘semantización’ del discurso político”, Comunicación y medios, n 7-8, pp. 47-52.

García Beaudoux, V., D’Adamo, O. y Slavinslky, G. (2005): Comunicación política y campañas electorales. Barcelona: Gedisa.

Hawkins, K. (2010): Venezuela's. Chavismo and populism in comparative perspective. Nueva York: Cambridge University Press.

Herrero, J. C. y Requeijo, P. (2014): “El discurso de campaña”, en Herrero, J. C. (ed.): Comunicación en campaña. Dirección de campañas electorales y marketing político. Madrid: Pearson, pp. 239-270.

Hirschfeld, J. (2015): “Obama accuses Trump of Exploiting Working-Class Fears”, nytimes.com, http://www.nytimes. com/2015/12/22/us/politics/president-obama-accuses-donald-trump-of-exploiting-working-class-fears.html [Consultado el 10/04/2016].

Holloway, J. (2002): Cambiar el mundo sin tomar el poder. El significado de la revolución de hoy. Buenos Aires: Herramienta. Iyengar, S. y Kinder, D. (1987): News that Matters. Chicago: University of Chicago Press.

Kepel, G. (2001): La Yihad. Expansión y declive del islamismo. Barcelona: Peninsula.

Kingdon J. W. (1984): Agendas, alternatives and public policies. Boston: Little, Brown \& Co.

Klemperer, V. (2014): LTI. La lengua del Tercer Reich. Apuntes de un filólogo. Barcelona: Minúscula.

Kurth, A. (2015): "ISIS is not a Terrorist Group", ForeignAffairs.com, https://www.foreignaffairs.com/articles/middle-east/ isis-not-terrorist-group [Consultado el 05/06/2016].

Laborda, X. (2012): Lágrimas de cocodrilo. Análisis del discurso político. Barcelona: UOC.

Laclau, E. (1977): Política e ideología en la teoría marxista. Capitalismo, fascismo, populismo. Londres: New Left Books. Lifton, R. (2003): Superpower syndrome: America's apocalyptic confrontation with the world. Nueva York: Nation Books. 
Mazzoleni, G. y Winfried, S. (1999): “Mediatization of politics: A Challenge for Democracy?”, Political Communication, 16, pp. 247-261.

McCombs, M. y Shaw, D. (1972): “The Agenda-Setting Function of Mass Media”, Public Opinion Quaterly, 36, pp.176-187.

McCombs, M. y Bell, T. (1996): “The agenda-setting role of mass communication”, en Salwen, M. y Stacks, D. (eds.): An integrated appproach to communication theary and research, New Jersey: Lawrence Erlbaum Associates, pp. 93-110.

Patriau, E. (2012): "El populismo en campaña! Discursos televisivos en candidatos presidenciales de la Región Andina (2005-2006)”, Colombia Internacional, 76, pp. 293-325.

Pérez Herrera, J. C. (2014): La comunicación en campaña: Dirección de campañas electorales y marketing político. Madrid, Pearson.

Reese, S. y Lewis, S. (2009): "Framing the war on terror: The internalization of policy in the US press", Journalism, $\mathrm{n}^{\circ} 10$ (6), pp. 777-797.

Riffkin, R. (2015): “Americans name Terrorism as No. 1 U.S. Problem”, Gallup.com, http://www.gallup.com/poll/187655/ americans-name-terrorism-no-problem.aspx?g_source=Politics\&g_medium=newsfeed\&g_campaign=tiles [Consultado el 5/04/2016].

Rodrigo-Mendizábal, I. (1999): "Del análisis del contenido al análisis del discurso”, en Van Dijk, T. A. Y Mendizábal I. R., Análisis del discurso social y político. Quito: Ediciones ABY-AYALA, pp. 103-168.

Seymour-Ure, C. (1974): The political impact of mass media. Beverly Hills: California, Sage Publications.

Stubbs. M. (1987): Análisis del discurso. Madrid: Alianza Editorial.

Tovar, J. (2014): La política exterior de Estados Unidos y la expansión de la democracia (1989-2009). Valencia: Tirant lo Blanch.

Tyndall, A. (2016): "Donald Trump, King of All Earned Media" en TyndallReport.com, http://tyndallreport.com/comment/20/5775/ [Consultado el 15/04/2016].

Valdés-Ugalde, J. L. y Duarte, F. (2013): “Del poder duro al poder inteligente. La nueva estrategia de seguridad de Barack Obama o de la sobrevivencia de la política exterior de Estados Unidos”, Norteamérica Revista Académica del CISAN-UNAM, vol. 8, no 2, pp. 41-69.

Van Dijk, T. A. y Mendizábal I. R. (1999): Análisis del discurso social y político. Quito: Ediciones ABY-AYALA. 
Van Dijk, T. A. (2002): “El análisis crítico del discurso y el pensamiento social”, Atenea Digital Universidad Pompeu Fabra, no 1 , pp. 1-7.

Weaver, D. H. (1997): “Canalización mediática ('agenda-setting') y elecciones en Estados Unidos”, CIC Cuadernos de Información y Comunicación, no 3, pp. 229-241.

Welch, M. (2006): "La cruzada de Estados Unidos contra el terror: explorando la religión y la militancia en el mundo post 11 de septiembre”, Revista Cenipec, no 2, pp. 165-192.

Anexo 1. Link de los artículos analizados por orden cronológico:

\section{TRUMP}

http://www.nytimes.com/politics/first-draft/2015/11/16/donald-trump-repeats-call-to-inspect-mosques-for-signs-ofterrorism/?_r=0

http://thehill.com/blogs/ballot-box/gop-primaries/donald-trump-american-muslim-database-special-id-absolutely http://www.cnbc.com/2015/11/25/donald-trump-says-he-can-predict-terrorism-i-can-feel-it.html http://edition.cnn.com/2015/12/02/politics/donald-trump-terrorists-families/

http://edition.cnn.com/2015/12/08/politics/donald-trump-ban-muslims/

http://edition.cnn.com/2015/12/13/politics/donald-trump-muslim-ban-state-of-the-union/

http://edition.cnn.com/2016/01/02/politics/donald-trump-barack-obama-hillary-clinton-created-isis/

http://thehill.com/blogs/ballot-box/gop-primaries/268614-trump-to-syrian-refugee-children-you-cant-come-here https://www.washingtonpost.com/politics/trump-says-torture-works-backs-waterboarding-and-much-worse/2016/02/17/4c9277be-d59c-11e5-b195-2e29a4e13425_story.html

\section{CLINTON}

http://edition.cnn.com/2015/11/04/politics/hillary-clinton-climate-change-syria-refugee-crises/ http://edition.cnn.com/2015/11/14/politics/hillary-clinton-democratic-debate-radical-jihadist/ http://www.cbsnews.com/news/in-dallas-hillary-clinton-weighs-in-on-syrian-refugee-crisis/ http://www.cbsnews.com/news/hillary-clintons-plan-for-dealing-with-isis/ http://www.cbsnews.com/news/hillary-clinton-we-need-to-take-action-now-on-guns-after-san-bernardino-shooting/ http://abcnews.go.com/Politics/hillary-clinton-calls-san-bernardino-shooting-suspects-isis/story?id=35611247 http://www.nbcnews.com/storyline/isis-terror/clinton-set-roll-out-plan-stop-spread-isis-n480376 http://abcnews.go.com/Politics/hillary-clinton-trump-isiss-best-recruiter/story?id=35848986 http://www.cbn.com/cbnnews/politics/2015/December/Hillary-Clinton-Its-Genocide/?Print=true http://www.businessinsider.com/hillary-clinton-donald-trump-muslim-veteran-cnn-town-hall-2016-1 